\title{
A Study on the Development of Cultural Policy and 'Cultural Economic Strategy' in Japan
}

\author{
Kibum Nam1), Kyoo Hoon Jo2)
}

\begin{abstract}
The Japanese Government announced the "Cultural Economic Strategy" at the end of 2017 and presented a frame of government cultural policy that approaches culture from an economic perspective. This study analyzes Japan's attempts from the perspective of cultural policy development and comparative cultural policy. In order to compare the cultural policy with historical development, the development of cultural policy through the previous research set the standards and framework for visual comparison. This study analyzed the significance and suggestions of "economic strategy." Based on such comparison, we recognized the concept and importance of culture and analyzed the area of cultural policy, the subject of cultural policy, and the viewpoint of cultural policy. Cultural arts and life culture, cultural democracy, cultural industry and cultural economy, national and international areas as cultural policy, cultural welfare and multi-culture, market and government (central and local government) analysis dimension was set and implication was derived using these standards.
\end{abstract}

Keywords: Cultural Policy, Japanese Cultural Policy, Cultural Economic Strategy, Comparative Cultural Policy

\section{Introduction}

By the end of 2017, the Japanese government announced its "Cultural Economic Strategy" to begin an attempt to frame a government-wide cultural policy that approaches culture from an economic perspective. It suggests a new approach that is quite different from previous cultural policies. It is necessary to evaluate the attempts of these new cultural policies and to suggest implications for Korean cultural policies through a comparative perspective, and to suggest ways to improve the quality of cultural policies. As there is no study analyzing Japanese culture and economic strategy, this study is also valuable in exploratory research.

Received(September 21, 2019), Review Result(1st: October 19, 2019, 2nd: November 30, 2019), Accepted(January 30, 2020)

1) (Professor, Corresponding Author) 14097 Dept. of Public Administration, Sungkyul Univ., Anyang-8-dong, Manan-gu, Anyang-si, Kyunggi-do, South Korea

email: nkb@sungkyul.ac.kr

2) (Ph.D course) 03967 Dept. of arts \& cultural management, Graduate school of Hongik Univ, Seoul, Korea

email: jkh660210@naver.com 
This study analyzes the attempts from the perspective of the development and cultural policy of Japan. To this end, through the previous studies on the comparison of cultural policy with the historical development of cultural policy, we set the standard of view and comparison of cultural policy development. The difference was compared with previous cultural policies. As a comparison standard, this study analyzed the concept of cultural concept and its importance, the area of cultural policy, and the subject of cultural policy. Based on these standards, implications are drawn through comprehensive analysis of the dimensions of the analysis of the culture and arts and living culture, the democratization of culture and cultural democracy, the cultural industry and cultural economy, and the national and international domains as cultural policy, cultural welfare and multiculturalism, the market and the government (central and local government).

\section{Development of Japanese Cultural Policy}

\subsection{Framework for Viewing Changes in Cultural Policy}

This study seeks to derive implications regarding the direction of cultural policy by exploring how Japanese cultural policy changed before and after the cultural economic strategy. To this end, the criteria for comparative analysis of the difference between before and after the cultural economic strategy should be determined first. These criteria can be extracted through comparative studies of cultural policy or a review of previous studies on the historical approach of cultural policy.

Cheol-Hyun Jung compared the cultural policies of the two Koreas, based on the purpose of the cultural policy, the subject of the cultural policy, and the process of the cultural policy[1]. Woo-Hyung Lee tried to find out the criteria based on importance, actors, intervention style, and policy target[2]. Kim Myeon examines the history of German cultural policy[3]. Traditionally, the sovereignty of cultural policy was not in the federal government but the local government. As the twentieth century entered, the slogan of cultural policy changed over time. The change was analyzed. The period of cultural policy as a propaganda tool of the empire (1933-45), the reconstruction of traditional arts and the restoration of cultural infrastructure (1945-68), the period of reform of social culture with a focus on the living culture of all people (1969-80) and the period of the practical change in cultural policy where the role of the market is important (1982-89) was proceed. After the unification, the global policy (1990-2000) "Corporation Germany" slogan has become important. Through the analysis of various 
perspectives and areas of cultural policy in the 21st century, Germany is actively promoting the cultural industry policy, and show that there are multiple areas of cultural policy, and that important actors have changed according to the core areas of cultural policy. Dong-Yeon Lee extended the change of the ideology of cultural policy from a narrow concept to a broad concept, from political and economic democracy to cultural democracy, and a multitude of lives in policy for minority cultural artists. It is to establish the principles of the transition to policies for the value of people and the development and distribution of various cultural resources[4].

This study discusses the status and changes of cultural economic strategy in Japanese cultural policy, focusing on the significance and importance of cultural and cultural policy, the domain of cultural policy, and the subject of cultural policy based on the comparative criteria and analytical categories of many scholars.

[Table 1] Comparative Criteria for Cultural Policy

\begin{tabular}{|l|l|l|l|l|}
\hline \multicolumn{1}{|c|}{$\begin{array}{c}\text { Comparative } \\
\text { Criteria }\end{array}$} & \multicolumn{1}{|c|}{$\begin{array}{c}\text { Cheol-Hyun } \\
\text { Jung }\end{array}$} & \multicolumn{1}{|c|}{$\begin{array}{c}\text { Woo-Hyung } \\
\text { Lee }\end{array}$} & Kim Myeon & \multicolumn{1}{|c|}{ Dong-Yeon Lee } \\
\hline $\begin{array}{l}\text { Importance of } \\
\text { Culture and } \\
\text { Cultural Policy }\end{array}$ & $\begin{array}{l}\text { Purpose of } \\
\text { Cultural Policy }\end{array}$ & $\begin{array}{l}\text { Ideal, } \\
\text { Characteristics, } \\
\text { Importance }\end{array}$ & $\begin{array}{l}\text { The slogan } \\
\text { of Cultural } \\
\text { Policy }\end{array}$ & $\begin{array}{l}\text { Expansion of the cultural } \\
\text { concept }\end{array}$ \\
\hline $\begin{array}{l}\text { Area of cultural } \\
\text { policy }\end{array}$ & $\begin{array}{l}\text { Process of } \\
\text { Cultural Policy }\end{array}$ & Policy target & $\begin{array}{l}\text { Area of } \\
\text { cultural } \\
\text { policy }\end{array}$ & $\begin{array}{l}\text { - Policy for the Value of } \\
\text { Multiple Life from Culture } \\
\text { and Artist Policy } \\
\text { - Development of various } \\
\text { cultural dimensions }\end{array}$ \\
\hline $\begin{array}{l}\text { Actors of Cultural } \\
\text { Policy }\end{array}$ & $\begin{array}{l}\text { Actors of } \\
\text { Cultural Policy }\end{array}$ & $\begin{array}{l}\text { Actors } \\
\text { intervention } \\
\text { style }\end{array}$ & $\begin{array}{l}\text { Actors of } \\
\text { Cultural } \\
\text { Policy }\end{array}$ & Cultural democracy \\
\hline
\end{tabular}

\subsection{Development of Japanese Cultural Policy}

This section presents the historical development of cultural policy before Japan's cultural economy strategy, focusing on the cultural concepts, the areas of cultural policy, and the actors of cultural policy. The time scope to examine is the period from the Meiji Restoration to before 'Cultural Economic Strategy'(2017).

1) After Meiji Restoration - 1945

The most powerful national cultural policy in Japan was probably after the Meiji Restoration[5]. It avoided colonization by Western powers and introduced western civilization at 
a rapid pace. In this movement of civilization, arts with roots in the West were also actively introduced. Also, a relatively important area of the cultural policy after the nation was to protect its own traditional culture. The protection of cultural property originated from the cataloging of cultural properties to be protected to brake the outflow of outstanding artworks leads to the modern cultural property protection law and its system.

2) 1945 - 1960: The absence of cultural policy

The government's cultural policy at this time was extremely passive, starting from a reflection on the state's cultural control during the war, excluding the country's involvement in the arts and culture, or following the acceptance of the civilian-led cultural policy of the victorious United States. Therefore, support for cultural arts activities was led by entrepreneurs in the private sector, rather than national support, and the government focused on protecting tangible and intangible cultural heritage related to Japan's unique cultural identity. Enactment of the Cultural Heritage Protection Act in 1950 is a representative example of the protection of cultural heritage.

3) 1960 - 1970: The beginning of cultural policy

While experiencing high growth in the 1960s, he made a series of movements to pursue quality of life and abundance of mind. Actively promoted. In 1968, the Ministry of Education was established by the Ministry of Education, Ministry of Education, Culture, Culture and Arts and Cultural Property Protection Policy.

4) 1970 - 2000: the era of cultural policy

With the advent of the 'Era of Culture' around 1980, the Cultural Authority had a complete art culture support system. Also, in the late 1980s, the Local Promotion Act was enacted to expand the facility maintenance for cultural promotion. Also, in 1990, the Messena Council, a corporate body, was established in 1990 to support corporate culture and arts support, thus sharing the role and solidarity of corporations, and breaking away from the traditional consciousness that cultural policy is exclusive to the state and public periods. As policy was required, cultural policy was promoted to promote living culture. The cultural concept of this period was extended to living culture, and cultural policy began to appear as an interest in new areas in cultural and art promotion.

5) 2000 - 2007 (Presentation of Cultural Economy Strategy) 
The Framework Act on Culture and Arts Promotion was passed in 2001, and the Japanese government expressed its willingness to intervene in the development of culture and art and formalized it as a legal system. Although the nature as a proclamation law that acknowledged the importance of cultural promotion was strong, it was a significant change in cultural policy to exemplify the areas of policy subjects such as art, media arts, cultural assets, and traditional arts. Under the Framework Act on Culture and Arts Promotion, the basic policy on the promotion of the first culture and arts was decided in 2002 by the Ministerial and established the basic policy every five years.

In May 2015, the Fourth Basic Policy (2015 2019) was finalized, setting the overall direction of cultural policy toward 2020. The key strategies of cultural policy presented in the fourth policy include the following five strategies[6] namely effective support for cultural and arts organizations, nurturing talented people who create cultural arts, solid succession of cultural arts for the next generation, promoting cultural diversity and mutual understanding at home and abroad, and improving the body to promote cultural arts. Every year, the policies for the promotion of culture and art are summarized in the white paper. Based on the legal system, the policy on culture and art has also changed to allow for more active government intervention.

Another significant change is the emergence of industrialization strategies at this time. Cultural industry policies began to attract attention as projects such as Cool Japan and Japanesque Modern were led by the Ministry of Economy, Trade and Industry[7]. However, Shin Byeong-dong said that the legal system supporting Japanese cultural policy at that time lacked the aspects of "creating a new cultural value" or "approval of multiple cultures"[8].

\section{Japan's Cultural Economy Strategy}

\subsection{Background of Cultural Economic Strategy}

On December 27, 2017, the Cabinet Office's Special Team on Culture and Economic Strategies and the Ministry of Culture published the 'Cultural Economy Strategy'. The purpose is to create a mechanism for sustainable development by creating new values by integrating various fields and cultures, such as industry and tourism, and effectively reinvesting the created values in the preservation, inheritance and creation of new cultural arts. In June 2017, it was decided to establish and implement a 'cultural economy strategy' in 'Basic Policies of Economic Management and Reform 2017[9]' and 'Future Investment Strategy 2017'[10]. 


\subsection{Composition and Content of Cultural Economy Strategy}

To analyze the composition and contents of the culture and economic strategy, This study reviewed the 'Cultural Economic Strategy'[11] and 'Overview of cultural and economic strategies'[12] announced in December 2017, and the 'Cultural Economy Strategy: Action Plan 2018[13]'. The researchers wanted to explore a comprehensive range. Cultural economic strategy is composed of the basic recognition, the background of strategic establishment, the future of the goal of cultural economic strategy, the six basic perspectives, and six key strategies. The summary and concrete yearly action plan are used to establish specificity and execution power.

1) Background of basic recognition and strategy establishment

With the growing importance of culture, to this study considered the importance of policies that will lead the culture as a driving force to raise the international status and accelerate economic growth based on the cultural and artistic assets of Japan. Under these basic perceptions, various sectors of the economic society such as tourism, sports, and industry can create synergy with cultural arts under the background of enactment of the Framework Act on Culture and Arts, revision of the Act on the Protection of Cultural Heritage, and the relocation of Kyoto to the Cultural Authority. It is trying to utilize cultural economic strategy.

2) Establishment and implementation of national strategies and future goals

Cultural economic strategy requires efforts in various fields that utilize culture as an important factor in determining industrial competitiveness, and government-related ministries work closely together to ensure that these efforts are organically linked. By creating a collaborative environment between NPOs, private actors, and the government aims to promote cultural investment through cultural policies, thereby creating a mechanism for sustainable economic and social development.

Through the establishment and execution of such national strategies, the aim is to develop and grow the culture and arts in the first place, to support cultural management that connects culture and arts to corporate values, to activate tourism based on culture and arts, and to focus on culture. By combining various resources, there is a need to create new industries and new markets. Furthermore, from the point of view of social involvement, the aim is to create a 'national cultural power' with an understanding of cultural diversity by promoting the understanding of culture by expanding the capacity and consumption of Japanese citizens to participate in cultural art activities. 
3) Six points of view as a strategy building foundation

The Cultural Economy Strategy proposes six basic perspectives to implement the strategy by mobilizing all policy tools[14]. First, continuous succession and development of a culture that aims for the future must be achieved. Second, a structure where investment in culture continues must be created. Third, the region should be activated in cultural economic activities. Fourth, Japan's brand value should be maximized by providing interactive international information. Fifth, realize social inclusion and multicultural society through cultural economic activities. Sixth, it presents six perspectives to create a cultural heritage that can be proud of future generations after the 2020 Olympics.

\section{4) Six key Strategies}

Six perspectives suggest six key strategies[15]: preservation of cultural and artistic resources(cultural assets), utilization of cultural and artistic resources(cultural assets), promotion of cultural creation activities, improvement of international existence, creation of new value-added value by spreading to surrounding areas, and reinforcement of promotion base of cultural economy strategy. Each key strategy suggests key activities related to the response direction.

First, as a response direction of the conservation strategy of cultural and artistic resources, it is suggested to reexamine the cultural festival protection system, reinforce the preservation measures for cultural property, and create a social atmosphere for cultural property protection and foster related experts.

Second, as a strategy to utilize cultural arts resources, tourism bases such as town centered on cultural property as a response direction will be utilized, support functions for promoting the utilization of cultural properties must be enhanced, the use of advanced technologies such as digitization of cultural properties must be expanded, and multilingual information when cultural properties are must be enhanced. Related personnel training is suggested.

Third is the promotion strategy of cultural creation. This includes enhancement of the environment in which people participate in cultural activities, promotion of living culture such as food and fashion, overseas information, appreciation of the culture and arts of vulnerable groups (children, the elderly, the disabled, etc.), maintenance of the creative environment, development of leading talents in culture creation, and strengthening domestic and foreign support. The national goal of the Olympic and Paralympic Cultural Programs is to respond to this strategy. 
Fourth is the strategy for improving international status. The countermeasures include bi-directional information sharing, including comprehensive and transversal propulsion accounts through department linkages to improve brand power using culture and arts, the active promotion of culture and arts overseas, and the introduction of Japanese culture.

Fifth is the strategy of creating new added value by spreading the surrounding areas through increasing connection with local cultural and art resources and regions, activating and improving local cultural and artistic activities, fostering local cultural talents, supporting cultural events through the use of public spaces, and cultural and artistic resources.

Lastly, it is a strategy to reinforce the foundation of cultural economic strategy. To this end, it includes the reorganization of the National Culture Agency, the reorganization of the regional cultural property protection function, and the review of new tasks. Incentives for investment in culture and art, plans for encouraging arts contributions, the National Museum's management certification system, awards for the merit of cultural economic activities, and the introduction of $1 \%$ public arts in public building facilities are included.

\section{5) Promotion and Execution of Strategy}

To implement the strategy, the progress of other policies must be considered, continuously reviewing it through listening to the opinions of related parties, drafting the cultural economic strategy action plan by year, and implementing the policy every year using the PDCA cycle. The annual action plan is composed of the yearly process table, which presents the basic policy, main policies, implementation, yearly progress, and performance indicators[16].

\section{Implications of Changes in Cultural and Economic Strategies}

As mentioned earlier, the importance of Japanese cultural policy gradually increased and its area expanded even before the cultural economic strategy. In addition, the central government has emerged at the forefront in the era when the civil sector, which acts at the local government and regional level in the main body of cultural policy, was the center of cultural policy. The concept expanded to the economy, and various ministries such as economic and industry were expanded to the subject of cultural policy. In extension of this trend, the cultural economy strategy expresses the time of presentation as the historical turning point of cultural policy. It is not an exaggeration to say that it is a transitional period. There are differences from previous cultural policies. This study discusses the differences concerning comparative criteria extracted through previous studies. 


\subsection{Deepen Awareness of the Importance of Culture}

In the basic perception of cultural economy strategy, culture is recognized externally as a determinant of national prestige, national competitiveness, and internal pride. Culture plays an important role in forming a national brand. Recognizing that people can inspire pride and a sense of belonging by recognizing cultural possibilities, the 2020 Olympics and Paralympic Games are considered the beginning of cultural policy. There is a clear difference from previous policies in that the perception of the importance of culture as a driving force for the development of industry and economy is firmly established. Culture is recognized as an important factor in determining the competitiveness of culture and industry as a driving force for economic growth. In addition, the cultural economy strategy shows the basic perception that cultural power is important in addition to the existing political, economic, and military powers as a determining factor. Emphasis is placed on the concept of cultural power, which emphasizes the importance of cultural arts in the area of living and culture.

\subsection{Expansion of the Scope of Cultural Policy}

Recent Japanese cultural policy shows the transition from cultural promotion to comprehensive cultural policy in various aspects. Formation of Special Team on Culture and Economic Strategy in Japan in March 2017, Enactment of Framework Act on Culture and Arts in June 2017, Announcement of Culture and Economy Strategy in December 2017, Establishment of Basic Plan for Culture and Art Promotion in March 2018, Culture and Strategy on 2018 The announcement of action plans has elaborated these steps.

An integrated link between various sectors and cultural-related policy activities is a characteristic of the comprehensive cultural policy seen in the cultural economy strategy. It is expanding spatially from local cultural policy to the international policy of international sector. It also includes a plan that extends from the promotion of pure culture and arts to the culture in the realm of life, and the cultural welfare area of multicultural living for inclusion and cultural creation and enjoyment of particular classes. There are also changes in the preservation and utilization of cultural property, which has traditionally been the center of cultural policy. With the expansion of the policies mentioned, the government intends to recognize the importance of non-designated cultural properties in addition to existing designated cultural properties and preparing new countermeasures. Policy interest in potential heritage is shown. 
Based on these perspectives on future cultures and cultural properties, the government proposes a nationwide and national response to take full advantage of the 2020 Olympic and Paralympic Games.

\subsection{Governance of Cultural Policy}

Along with the extended area of cultural policy, the diversity of the subjects of cultural policy and the linkage between the various subjects can be characterized. In line with the shift from cultural arts promotion to comprehensive cultural policies, cultural economic strategies include the significant use of the roles of various government agencies, local and regional actors, government and non-governmental organizations. It presents policy enforcement and promotion mechanisms through comprehensive and cross-linking, including collaboration within the central government, cooperation between government and local governments, and cooperation between government and non-governmental organizations.

The exploratory attempt of this study can provide value to provide important implications for the consideration of the direction of cultural policy. However, it was difficult to analyze the execution process or the performance in a short time since the cultural economic strategy was started. Therefore, it was limited to examine the whole process of the cultural economic strategy comprehensively In the future, more in-depth studies on the entire process of cultural economic strategy should be supplemented.

\section{References}

[1] Jung Chul-Hyun, A Comparative Study of Cultural Policy Between South Korea and North Korea, Journal of Social Science, (2006), Vol.37, No.2, pp.1-24.

[2] Lee Woo-young, Comparative Study of Cultural Policy between North and South Korea, Korea Institute for National Unification, (1994)

[3] Kim Myun, German cultural policy and Nation Branding, The Journal of Culture Contents, (2016), Vol.8, pp.139-171.

[4] Lee Dong-yeon, A Prospect of Cultural Policy for Preparing a Cultural Society, Study on Democratic Society and Policy, (2005), Vol.6, pp.184-209.

[5] https://synodos.jp/culture/14046, Dec 2 (2019)

[6] Miura Hiroki et al., Korea's Cultural Policy and the World's Cultural Policy, Korea Research Institute, 
(2018), pp.49-65.

[7] Kang Sung-woo, A Study of Cultural Policy and Cultural Industries in Japan with Main Focus on the Policies of the METI(Ministry of Economy, Trade and Industry, Keizai - sangyō - shō), Humanities and Science Research, (2016), No.51, pp.99-115.

[8] Shin Byeong-dong, Legal Structure of Cultural Policy in Japan, The Journal of Sports and Entertainment Law, (2008), Vol.11, No.3, pp.173-197, DOI: 10.19051/kasel.2008.11.3.173

[9] https://www5.cao.go.jp/keizai-shimon/kaigi/cabinet/2017/decision0609.html, Dec 2 (2019)

[10] https://www.kantei.go.jp/jp/singi/keizaisaisei/pdf/miraitousi2017_t.pdf, Dec 2 (2019)

[11] Cultural economic strategy(文化経濟戰略), Agency for Cultural Affairs, (2017)

[12] 'Overview of cultural and economic strategies(文化経濟戰略の全体像), Agency for Cultural Affairs, (2017)

[13] Cultural Economy Strategy: Action Plan 2018(文化経濟戰略: アクションプラン2018), Agency for Cultural Affairs, (2018)

[14] Cultural economic strategy(文化経濟戰略), Agency for Cultural Affairs, (2017), pp.7-13.

[15] Cultural economic strategy(文化経濟戰略), Agency for Cultural Affairs, (2017), pp.14-33.

[16] Cultural Economy Strategy: Action Plan 2018(文化経濟戰略: アクションプラン2018), Agency for Cultural Affairs, (2018), p.4. 